\title{
Exploring polypharmacy burden among elderly patients with chronic diseases in Chinese community: a cross-sectional study
}

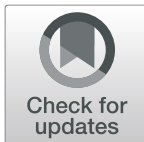

Yongli Wang ${ }^{1,2}$, Xiaodan $\mathrm{Li}^{2}$, Dongmei Jia ${ }^{2}$, Beilei Lin' ${ }^{1}$, Bo Fu ${ }^{1}$ Bei Qi ${ }^{1}$ and Zhenxiang Zhang ${ }^{1 *}$

\begin{abstract}
Background: In the long-term use of multiple medications for elderly patients diagnosed with chronic diseases, medication problems are prominent, which seriously reduces their quality of life. The burden of medications of patients critically affects their medication beliefs, behaviors and disease outcomes. It may be a solution to stress the burden of medications of patients. Its medication issues develops a novel perspective. The present study aimed to exploit the Chinese version of Living with Medicines Questionnaire-3(C-LMQ-3) to quantify the medicines burden of elderly patients diagnosed with chronic diseases in China, and evaluate the relevant demographic characteristics of sub-populations with high medicines burden.
\end{abstract}

Methods: The survey was distributed to elderly patients aged $\geq 60$ years with chronic disease by using $\geq 5$ medicines, C-LMQ-3 scores and domain scores were compared by the characteristics of elderly patients by employing descriptive statistics and performing statistical tests.

Results: On the whole, 430 responses were analyzed, and the participants were aged between 60 and 91 years, with the average age of 73.57 years (SD: 7.87). Most of the responses were female (61.7\%) with middle school education (38.5\%). Moreover, $54.1 \%$ of the participants lived with spouse only, $16.2 \%$ had both spouse and children, and $10.0 \%$ lived alone. As indicated from regression analysis, higher C-LMQ-3 scores were associated with those who were with low education level, 60-69 years-old, using $\geq 11$ medicines, using medicines $\geq 3$ times a day, income per month $(\mathrm{RMB}) \leq 3000$, and who having higher monthly self-paid medication (RMB) $\geq 300(p<0.01)$. Burden was mainly driven by cost-related burden, concerns about medicines, and the lack of autonomy over medicine regimens.

Conclusions: This study presents the preliminary evidence to elderly patients diagnosed with chronic diseases in mainland China that pay attention to multiple medications burden may help reduce the Drug Related Problems, whereas some elderly patients have a higher burden of medication. Chinese health care providers are required to primarily evaluate and highlight such patients, and formulate relevant intervention strategies to ensure medication adherence and daily medication management of elderly patients with polypharmacy.

Keywords: Medicine, Medicine burden, Patient-reported outcome, Multi-morbidity, Living with Medicines Questionnaire

\footnotetext{
* Correspondence: zhangzx6666@126.com

'School of Nursing and Health, Zhengzhou University, No.100 Science Avenue, Henan, Zhengzhou, China

Full list of author information is available at the end of the article
}

C C The Author(s). 2021 Open Access This article is licensed under a Creative Commons Attribution 4.0 International License, which permits use, sharing, adaptation, distribution and reproduction in any medium or format, as long as you give appropriate credit to the original author(s) and the source, provide a link to the Creative Commons licence, and indicate if changes were made. The images or other third party material in this article are included in the article's Creative Commons licence, unless indicated otherwise in a credit line to the material. If material is not included in the article's Creative Commons licence and your intended use is not permitted by statutory regulation or exceeds the permitted use, you will need to obtain permission directly from the copyright holder. To view a copy of this licence, visit http://creativecommons.org/licenses/by/4.0/. The Creative Commons Public Domain Dedication waiver (http://creativecommons.org/publicdomain/zero/1.0/) applies to the data made available in this article, unless otherwise stated in a credit line to the data. 


\section{Introduction}

In 2009, the World Health Organization (WHO) defined "multi-morbidity" as having two or more chronic diseases. Multi-morbidity is recognized as a common problem, mainly occurring in the elderly. One of the reasons is that population ageing is a global phenomenon [1]. As reported from the existing study, $61.7-86.3 \%$ of the elderly suffer from different chronic diseases in China [24]. However, according to the recently achieved data from the China Health and Retirement Longitudinal Study, physical multi-morbidity increased with age and was more common in poorer regions [5]. As suggested from the relevant literature on the multi-morbidity of chronic diseases among the elderly in China [2, 6, 7], the most common six kinds of chronic diseases were found, including hypertension, diabetes mellitus, coronary heart disease, stroke, hyperlipidemia and chronic obstructive pulmonary disease (COPD).

Medicines are the most commonly used medical technology to treat chronic diseases, and elderly patients often need to use multiple medicines due to multiple chronic diseases [8-10]. As reported from literature, $\geq 5$ medicines are the most commonly used definition of polypharmacy $[8,11]$. Polypharmacy contributes to increases the risk for a Drug Related Problems (DRPs) (e.g., adverse medication events [12], decreased medication adherence [13], increased hospitalization [14],cognitive impairment, falls and increased mortality [15]). As revealed from a systematic review [16], medication burden acts as a core factor affecting a patient's beliefs about medication adherence and health status, and to some extent reflects the patient's attitude and willingness and ability to handle medication use $[14,17]$. Therefore, measurement of medication burden may provide an important perspective for helping to reduce these medication-related problems and improve adherence.

Recently, as polypharmacy becomes widespread, a tool has been developed and validated by Krska et al. in the UK, which specifically aims to measure medicine-related burden in daily life-the Living with Medicines Questionnaire (LMQ) [18-20].The LMQ originated from qualitative interviews with patients who were diagnosed with multi-morbidity and using multiple medicines [21]. The LMQ can assess the patient's medicine-related burden (e.g., side effects, effectiveness, general concerns, and cost burden [20]). As indicated from existing studies, the tool exhibits high reliability and effectiveness, and has been employed in numerous nations (e.g., Australia, Belgium, the Netherlands, New Zealand, Qatar and the United Kingdom) [22-25]. Furthermore, the instrument has also been translated and validated for use in an elderly Chinese population- the C-LMQ-3 [26].

There are very few studies in China that report experiences of medication burden for elderly patients with multi-morbidity using multiple medicines. Research studies on both multi-morbidity and the burden of medication for patients with chronic diseases shift their stress to economic aspects of treatment burden [27]. Medicine burden refers to a different construct, and rare studies in China have explored the burden which medicines can impose on peoples' daily lives (e.g., side effects and other interferences [27]). For this reason, this study aimed to use C-LMQ-3 to quantify the medicines burden of elderly patients diagnosed with chronic diseases in China, as well as assess the relevant socio demographic characteristics of subpopulations with high medicines burden.

\section{Materials and methods}

\section{Setting, Study Population, and Sample selection}

The present study was a cross-sectional correlational design. Potential participants were recruited based on convenience sampling in Zhengzhou from January to August 2020. Eligible participants were identified by screening residents' health records in three community health service institutions to ensure that they had at least two chronic diseases. The following inclusion criteria were employed: (1) aged $\geq 60$ years (abiding by the Law of the People's Republic of China on the Protection of the Rights and Interests of the Elderly); (2) diagnosed with at least two chronic diseases (chronic diseases including hypertension, diabetes mellitus, coronary heart disease, stroke, hyperlipidemia and COPD); (3) using $\geq 5$ medications for more than 3 months; and (4) willing to participate in this study and provide informed consent. Individuals with cognitive impairments or other serious physical diseases who were unable to respond appropriately to the investigation were excluded from the study.

To ensure adequate statistical power, the sample size was calculated with the $G^{*}$ Power 3.1 in a multiple regression analysis with power set at $0.80, \alpha=0.05$ [28]. A medium effect size was 0.15 [29], and the number of dependent variables was 12 . The resultant sample size was at least 148 samples required, leading to a $20 \%$ inefficiency rate.

\section{The survey Tool}

This study used the C-LMQ-3 translated by the team of this study [26], which consisted of 39 items in eight domains (i.e., relationships with health professionals, practicalities, interferences, effectiveness, side effects, concerns, cost and autonomy, scored at a 5-point scale from strongly agree to strongly disagree). Total LMQ-3 scores range from 39 to 195; higher scores indicate greater burden associated with medicine use. The Cronbach's alpha for C-LMQ-3 was reported as 0.855 in elderly patients diagnosed with chronic diseases. The $\mathrm{C}$ - 
Table 1 Demographic characteristics of participants $(n=430)$

\begin{tabular}{|c|c|c|c|c|}
\hline Characteristic & $\mathrm{n}(\%)$ & score $(` x \pm s)$ & $t / F$ value & $P$ \\
\hline \multicolumn{5}{|l|}{ Age(years) } \\
\hline $60 \sim$ & $116(27.0)$ & $113.53 \pm 9.39$ & $7.624^{b}$ & 0.001 \\
\hline $70 \sim$ & $216(50.2)$ & $114.34 \pm 11.80$ & & \\
\hline $80 \sim$ & $98(22.8)$ & $109.13 \pm 11.39$ & & \\
\hline \multicolumn{5}{|l|}{ Gender } \\
\hline Male & 164(38.1) & $112.17 \pm 11.08$ & $-1.094^{\mathrm{a}}$ & 0.274 \\
\hline Female & $266(61.7)$ & $113.39 \pm 11.38$ & & \\
\hline \multicolumn{5}{|l|}{ Education level } \\
\hline Primary school or less & $69(16.0)$ & $116.62 \pm 10.29$ & $12.168^{b}$ & $<0.001$ \\
\hline Middle school & $166(38.5)$ & $115.28 \pm 10.35$ & & \\
\hline High school & 136(31.6) & $110.45 \pm 11.02$ & & \\
\hline College or above & 59(13.7) & $107.71 \pm 12.41$ & & \\
\hline \multicolumn{5}{|l|}{ Marital status } \\
\hline Unmarried & $3(0.7)$ & $118.67 \pm 7.51$ & $1.136^{\mathrm{b}}$ & 0.334 \\
\hline Married & $313(72.6)$ & $112.99 \pm 11.01$ & & \\
\hline Divorce & $10(2.3)$ & $107.20 \pm 11.60$ & & \\
\hline Widowed & 104(24.1) & $113.13 \pm 12.02$ & & \\
\hline \multicolumn{5}{|l|}{ Primary caregiver } \\
\hline Spouse & 138(32.0) & $112.12 \pm 8.84$ & $2.984^{b}$ & 0.019 \\
\hline Child & 154(35.7) & $111.53 \pm 10.21$ & & \\
\hline Nursing workers & $39(9.0)$ & $114.67 \pm 15.15$ & & \\
\hline No & $86(20.0)$ & $116.22 \pm 13.63$ & & \\
\hline Other & $13(3.0)$ & $111.00 \pm 12.28$ & & \\
\hline \multicolumn{5}{|l|}{ Income per month(RMB) } \\
\hline$<2000$ & 83(19.3) & $116.93 \pm 10.13$ & $17.315^{b}$ & $<0.001$ \\
\hline $2000 \sim$ & 149(34.6) & $115.83 \pm 11.20$ & & \\
\hline $3000 \sim$ & 135(31.3) & $110.01 \pm 10.06$ & & \\
\hline$>4000$ & $63(14.6)$ & $107.03 \pm 11.37$ & & \\
\hline \multicolumn{5}{|l|}{ Living status } \\
\hline Lives with spouse only & 233(54.1) & $113.31 \pm 10.23$ & $0.199^{b}$ & 0.897 \\
\hline Lives with children only & $84(19.5)$ & $112.58 \pm 12.46$ & & \\
\hline Lives with both spouse and children & $70(16.2)$ & $112.33 \pm 11.86$ & & \\
\hline Lives alone & $43(10.0)$ & $112.51 \pm 13.38$ & & \\
\hline \multicolumn{5}{|l|}{ Health conditions(diagnoses) } \\
\hline High blood pressure & $362(84.0)$ & $112.95 \pm 11.37$ & -0.095 & 0.924 \\
\hline Stroke & 199(46.2) & $113.20 \pm 11.22$ & -0.466 & 0.641 \\
\hline Diabetes & 255(59.2) & $113.73 \pm 11.22$ & -1.794 & 0.074 \\
\hline Hyperlipidemia & $281(65.2)$ & $111.99 \pm 19.70$ & 2.385 & 0.022 \\
\hline Coronary heart disease & 254(58.9) & $112.30 \pm 10.74$ & 1.383 & 0.176 \\
\hline Chronic obstructive pulmonary disease & 134(31.1) & $115.22 \pm 10.72$ & -2.867 & 0.004 \\
\hline \multicolumn{5}{|l|}{ Number of medicines } \\
\hline $5 \sim 10$ & 174(40.4)) & $109.71 \pm 10.31$ & $25.901^{b}$ & $<0.001$ \\
\hline $11 \sim 15$ & 203(47.1)) & $113.41 \pm 11.15$ & & \\
\hline$>15$ & $53(12.3)$ & $121.66 \pm 9.86$ & & \\
\hline
\end{tabular}


Table 1 Demographic characteristics of participants $(n=430)$ (Continued)

\begin{tabular}{|c|c|c|c|c|}
\hline Characteristic & $\mathrm{n}(\%)$ & score $(x \pm s)$ & $t / F$ value & $P$ \\
\hline \multicolumn{5}{|l|}{ Frequency of medicines } \\
\hline Once per day & $49(11.4)$ & $105.16 \pm 9.97$ & $16.367^{b}$ & $<0.001$ \\
\hline Twice per day & $91(21.1)$ & $110.36 \pm 11.49$ & & \\
\hline Three per day & $224(52.0)$ & $114.16 \pm 10.71$ & & \\
\hline More than three times per day & $66(15.3)$ & $118.06 \pm 10.09$ & & \\
\hline \multicolumn{5}{|c|}{ Monthly self-paid medication(RMB) } \\
\hline$<100$ & $44(10.2)$ & $104.20 \pm 9.69$ & $13.573^{b}$ & $<0.001$ \\
\hline $100 \sim$ & $98(22.7)$ & $110.28 \pm 9.93$ & & \\
\hline $300 \sim$ & $128(29.7)$ & $113.64 \pm 11.57$ & & \\
\hline $500 \sim$ & 129(29.9) & $115.89 \pm 10.12$ & & \\
\hline $800 \sim$ & $31(7.2)$ & $118.42 \pm 12.37$ & & \\
\hline
\end{tabular}

Tips: ${ }^{a}$ represents T value; ${ }^{\mathrm{b}}$ represents $F$ value

LMQ-3 also includes a visual analogue scale (VAS), which measures global burden scored from 0 to 10 .

\section{Data Collection}

Data were collected during community elderly health checkups, free consultations, health lectures or home visits. The investigators were trained in the purpose of the investigation, the method of using the questionnaire, and the precautions. Data were collected by eight investigators, four researchers, and four community-medical staff. The questionnaire was filled out independently by the survey participants. The questionnaire issuer was permitted to read out the contents of the questionnaire separately to help respondents complete the questionnaire, and check whether there were any problems (e.g., omissions and missing responses). Furthermore, all the questionnaires were returned on the spot after completion.

\section{Statistical analysis}

All data were inputted into Microsoft Office Excel 2016 software, and IBM SPSS 21.0 was used to conduct the statistical analysis. Mean, Standard Deviation (SD), frequencies were adopted to describe the demographic characteristics of elderly patients with chronic disease. Based on analysis of variance and t-test, the multiple medicine related-burden level of the participants was analyzed. Multiple linear regression analysis was used to analyze the factors of multiple medicines relatedburden.

\section{Results}

\section{General Characteristics of patients}

Among the 527 eligible patients identified, a total of 469 patients in the initial study population agreed to be surveyed, and $453(96.6 \%)$ responded to the survey. A completion rate of $94.9 \% \quad(n=430)$ was gained after excluding those who provided an incomplete survey
( $n=23,5.1 \%)$ and those who withdrew from the halfway survey $(n=16,3.4 \%)$. The common reasons for withdrew from the halfway survey involved a lack of time $(n=3)$, a lack of interest $(n=9)$ and fear of disclosure of personal health information $(n=4)$.

The demographic and medical characteristics of the 430 respondents are listed in Table 1. The participants were aged between 60 and 91 years, and the average age was 73.57 years (SD: 7.87). Most were female (61.7\%) and had a middle school education (38.5\%). Furthermore, $54.0 \%$ of the participants had a monthly income less than 3000 Renminbi (RMB). Moreover, $54.1 \%$ of the participants lived with spouse only, $16.2 \%$ with both spouse and children, and $10.0 \%$ lived alone. On average, participants took $10.1 \pm 3.5$ prescription medications, ranging from $5(n=52)$ to $18(n=1)$, the median value of the prescribed medication by patients was 11 . Most used 5-10 medicines $(n=174,40.4 \%)$ or $11-15$ medicines $(203,47.1 \%)$ and used medicines twice $(91,21.1 \%)$ or three times daily $(224,52.0 \%)$.

\section{Assessment of Polypharmacy Burden}

Table 2 lists the responses to individual statements in the C-LMQ-3 and 8 domains score, the C-LMQ-3 total scores were normally distributed, i.e., mean 112.9 (SD = 11.3), range 84-145 (maximum possible range 39-195). VAS scores were skewed to higher values with a median (range) of $6(0-10)$ and mean 5.4 $(\mathrm{SD}=1.7)$. Moreover, the VAS-burden scores displayed a strong-positive relationship with C-LMQ-3 total scores (Spearman's $\mathrm{r}=$ $0.869 ; p<0.001)$. The top 10 items with the maximal scores in C-LMQ-3 are listed in Table 3.

\section{Factors associated with polypharmacy burden}

Table 1 presents the results of the differences in CLMQ-3 scores between the demographic characteristics and medicine use of different elderly patients diagnosed 
Table 2 Responses to individual statements in the C-LMQ-3 and 8 domains score $(n=430)$

\begin{tabular}{|c|c|c|c|}
\hline Statements /domains & $\begin{array}{l}\text { Agree/ } \\
\text { Strongly } \\
\text { Agree } \\
\text { N (\%) }\end{array}$ & $\begin{array}{l}\text { Neutral } \\
\text { opinion } \\
\text { N (\%) }\end{array}$ & $\begin{array}{l}\text { Disagree/ } \\
\text { Strongly } \\
\text { Disagree } \\
\mathrm{N}(\%)\end{array}$ \\
\hline \multicolumn{4}{|l|}{ Practical difficulties (6 items; Mean $(S D)=17.2(2.5)$ ) } \\
\hline I find getting my prescriptions from the doctor difficult & $113(26.2)$ & 134(31.2) & 183(42.6) \\
\hline I am comfortable with the times I should take my medicines & 262(60.9) & $93(21.6)$ & $75(17.5)$ \\
\hline I am concerned that I may forget to take my medicines & 207(48.1) & 132(30.7) & $91(21.2)$ \\
\hline It is easy to keep my medicines routine & $250(58.1)$ & 123(28.6) & $57(13.3)$ \\
\hline $\begin{array}{l}\text { I find using my medicines difficult (e.g.: taking the medication from the package, keeping in mind the } \\
\text { precautions for medication use, etc.). }\end{array}$ & $216(50.2)$ & $71(16.5)$ & 143(33.3) \\
\hline I have to put a lot of planning and thought into taking my medicines & 107(24.9) & 163(37.9) & $160(37.2)$ \\
\hline \multicolumn{4}{|l|}{ lack of effectiveness (5 items; Mean $(S D)=13.3(2.6)$ ) } \\
\hline My medicines prevent my condition getting worse & 219(50.9) & $160(37.2)$ & $51(11.9)$ \\
\hline My medicines live up to my expectations & 208(48.4) & 164(38.1) & $58(13.5)$ \\
\hline My medicines allow me to live my life as I want to & 205(47.7) & 102(23.7) & 123(18.6) \\
\hline My medicines are working & $232(54.0)$ & $114(26.5)$ & $84(19.5)$ \\
\hline The side effects are worth it for the benefits I get from my medicines & $181(42.1)$ & 159(37.0) & $90(20.9)$ \\
\hline \multicolumn{4}{|l|}{ Cost-related burden ( 3 items; Mean $(S D)=9.4(2.3)$ ) } \\
\hline I worry about paying for my medicines & 229(53.3) & $91(21.1)$ & $110(25.6)$ \\
\hline I sometimes have to choose between buying basic essentials or medicines & 103(24.0) & 143(33.3) & 184(42.8) \\
\hline I have to pay more than I can afford for my medicines. & 167(38.8) & 161(37.4) & 102(23.8) \\
\hline \multicolumn{4}{|l|}{ Communication/relationships with HCPs (5 items; Mean (SD) = $13.6(3.4)$ ) } \\
\hline I trust the judgement of my doctor(s) in choosing medicines for me. & 293(68.1) & 49(11.4) & $88(20.5)$ \\
\hline My doctor(s) listen to my opinions about my medicines & 218(50.7) & $99(23.0)$ & 113(26.3) \\
\hline My doctor takes my concerns about side effects seriously. & 164(38.1) & $145(33.7)$ & $121(28.1)$ \\
\hline I get enough information about my medicines from my doctor(s) & $256(59.5)$ & $90(21.0)$ & $84(19.5)$ \\
\hline The health professionals providing my care know enough about me and my medicines & 159(37.0) & $160(37.2)$ & $111(25.8)$ \\
\hline \multicolumn{4}{|l|}{ Concerns about medicine use ( 7 items; Mean $(S D)=21.8(4.1)$ ) } \\
\hline I worry that I have to take several medicines at the same time & 213(49.5) & $73(17.0)$ & 144(33.5) \\
\hline I would like more say in the brands of medicines I use & 203(47.2) & $70(16.3)$ & 157(36.5) \\
\hline I feel I need more information about my medicines & 204(47.4) & 138(32.1) & $88(20.5)$ \\
\hline I am concerned about possible damaging long-term effects of taking medicines & 194(45.1) & $50(11.6)$ & 186(43.3) \\
\hline I am concerned that I am too reliant on my medicines & 178(41.4) & 129(30.0) & 123(28.6) \\
\hline I am concerned that my medicines interact with eating habits (other food, alcohol, drinks, etc.). & $101(23.5)$ & 129(30.0) & 200(46.5) \\
\hline I worry that my medicines may interact with each other & 150(34.9) & 171(39.8) & 109(25.3) \\
\hline \multicolumn{4}{|l|}{ Side-effect-burden (4 items; Mean (SD) = $11.9(1.9)$ ) } \\
\hline The side effects I get are sometimes worse than the problems for which I take my medicines & 205(47.7) & 152(35.3) & 73(17.0) \\
\hline The side effects that I get from my medicines interfere with my day to day life & 143(33.3) & 149(34.7) & 138(32.1) \\
\hline The side effects I get from my medicines are bothersome & 147(34.2) & 173(40.2) & $110(25.6)$ \\
\hline The side effects I get from my medicines adversely affect my wellbeing & $70(16.3)$ & 106(24.6) & 254(59.1) \\
\hline \multicolumn{4}{|l|}{ Interference to day-to-day life (6 items; Mean (SD) = 17.4 (2.6)) } \\
\hline My medicines interfere with my social or leisure activities & $109(25.3)$ & 256(59.6) & $65(15.1)$ \\
\hline Taking medicines affects my going out (walking, Cycling, driving, etc.) & $81(18.8)$ & 159(37.0) & 190(44.2) \\
\hline My medicines interfere with my social relationships with (family, friends, colleagues) & 64(14.9) & 132(30.7) & 234(54.4) \\
\hline Taking medicines causes problems with daily tasks & 135(31.4) & $218(50.7)$ & $77(17.9)$ \\
\hline
\end{tabular}


Table 2 Responses to individual statements in the C-LMQ-3 and 8 domains score $(n=430)$ (Continued)

\begin{tabular}{|c|c|c|c|}
\hline Statements /domains & $\begin{array}{l}\text { Agree/ } \\
\text { Strongly } \\
\text { Agree } \\
\text { N (\%) }\end{array}$ & $\begin{array}{l}\text { Neutral } \\
\text { opinion } \\
\mathrm{N}(\%)\end{array}$ & $\begin{array}{l}\text { Disagree/ } \\
\text { Strongly } \\
\text { Disagree } \\
\text { N (\%) }\end{array}$ \\
\hline My medicines interfere with my sexual life & 79(18.4) & 135(31.4) & $216(50.2)$ \\
\hline My life revolves around using medicines & 170(39.5) & 193(44.9) & $67(15.6)$ \\
\hline \multicolumn{4}{|l|}{ Autonomy/control (3 items; Mean (SD) = 8.5 (2.2)) } \\
\hline I can vary the dose of the medicines I take & $231(53.7)$ & 133(30.9) & $66(15.4)$ \\
\hline I can choose whether or not to take my medicines & $181(42.1)$ & $100(23.3)$ & 149(43.6) \\
\hline I can vary the times I take my medicines & 154(35.8) & $147(34.2)$ & $129(30.0)$ \\
\hline
\end{tabular}

with chronic diseases. Significant differences were identified in the age, education level, primary caregiver, income per month (RMB), types of medicine, frequency of medicines, monthly self-paid medication (RMB) and burden of multiple medications among elderly patients diagnosed with chronic diseases $(P<0.05)$. No significant differences were reported in burden of multiple medications among elderly patients diagnosed with chronic diseases regarding gender, marital status, living status, and health conditions $(P>0.05)$.

Table 4 lists the independent variable assignment in the fitted multiple linear regression model. Table 5 shows results from the multiple linear stepwise regression analysis to determine factors associated with multiple medicines burden of elderly patients diagnosed with chronic diseases. Age, education level, primary caregiver, income per month (RMB), number of medicines, frequency of medicine use, monthly self-paid medication (RMB) displayed noticeable relationships to multiple medicines burden. Elderly patients with relatively young age, low education level, low per capita economic income, higher numbers of medicines, high frequency of daily use and high monthly selfpayment medication fees may be subject to heavy multiple medicine burden. No multicollinearity was identified here, since the tolerance of each variable was between 0.82 and $0.97,>0.25$, and variance inflation factors for the mentioned variables ranged from 1.03 to 1.22 , both $<10.0$.

\section{Discussion}

In the present study, the C-LMQ-3 was used. It was reported that a relatively heavy burden of multiple medications is imposed on elderly patients diagnosed with chronic diseases in China, the C-LMQ-3 total scores were mean $112.9 \pm 11.3$, range 84-145 (maximum possible range 39-195). As indicated from domain analysis, the main drivers of burden included (i) cost-related burden (ii) concerns about medicines, as well as (iii) the lack of autonomy over medicine regimens. Multiple linear regression indicated significantly higher burden in patients with low education level, aged 60-69 years, using $\geq 11$ medicines, using medicines $\geq 3$ times a day, income per month $(\mathrm{RMB}) \leq 3000$, and having higher monthly selfpaid medication $(\mathrm{RMB}) \geq 300$. In addition, governments, health professionals and pharmacists should place the stress of their interventions on the mentioned populations to reduce their medicines burden and help them make optimal use of their medicines.

Table 3 The top 10 items with the highest scores in C-LMQ-3

\begin{tabular}{|c|c|c|}
\hline Item & $\begin{array}{l}\text { score( } x \pm \\
\text { s) }\end{array}$ & sort \\
\hline 3. I worry about paying for my medicines & $3.37 \pm 1.05$ & 1 \\
\hline 7. I feel I need more information about my medicines & $3.37 \pm 0.94$ & 2 \\
\hline 19. The side effects I get are sometimes worse than the problems for which I take my medicines & $3.33 \pm 0.78$ & 3 \\
\hline 8. I am concerned that I may forget to take my medicines & $3.31 \pm 0.92$ & 4 \\
\hline 39. My life revolves around using medicines & $3.28 \pm 0.78$ & 5 \\
\hline 4. I worry that I have to take several medicines at the same time & $3.24 \pm 1.07$ & 6 \\
\hline 31. I have to pay more than I can afford for my medicines. & $3.22 \pm 0.94$ & 7 \\
\hline $\begin{array}{l}\text { 27. I find using my medicines difficult (e.g.: taking the medication from the package, keeping in mind the precautions for } \\
\text { medication use, etc.). }\end{array}$ & $3.20 \pm 0.95$ & 8 \\
\hline 6. I would like more say in the brands of medicines I use & $3.18 \pm 1.24$ & 9 \\
\hline 34. My medicines interfere with my social or leisure activities & $3.16 \pm 0.76$ & 10 \\
\hline
\end{tabular}


Table 4 Description of the assignment of independent variables

\begin{tabular}{|c|c|c|c|c|}
\hline Independent variable & \multicolumn{4}{|c|}{ Assignment method } \\
\hline Age(years) & \multicolumn{4}{|c|}{$1=60 \sim ; 2=70 \sim ; 3=80 \sim$} \\
\hline Education & \multicolumn{4}{|c|}{$1=$ Primary school or less; $2=$ Middle school; $3=$ High school; $4=$ College or above } \\
\hline Income per month(RMB) & \multicolumn{4}{|c|}{$1=<2000 ; 2=2000 \sim ; 3=3000 \sim ; 4=4000 \sim$} \\
\hline Primary caregiver $(\mathrm{Xg})$ & (1) & (2) & (3) & (4) \\
\hline Spouse & $\mathrm{X} 1=1$ & $x 2=0$ & $x 3=0$ & $X 4=0$ \\
\hline Child & $\mathrm{X} 1=0$ & $X 2=1$ & $\mathrm{X} 3=0$ & $X 4=0$ \\
\hline Nursing workers & $\mathrm{X} 1=0$ & $X 2=0$ & $x 3=1$ & $X 4=0$ \\
\hline No & $\mathrm{X} 1=0$ & $\times 2=0$ & $x 3=0$ & $X 4=1$ \\
\hline Other owever, according to the recently achieved data fro & $X 1=0$ & $X 2=0$ & $\mathrm{X} 3=0$ & $x 4=0$ \\
\hline Types of medicines(kinds) & \multicolumn{4}{|c|}{$1=5 \sim 10 ; 2=11 \sim 15 ; 3=>15$} \\
\hline Monthly self-paid medication(RMB) & \multicolumn{4}{|c|}{$1=<100 ; 2=100 \sim ; 3=300 \sim ; 4=500 \sim ; 5=800 \sim$} \\
\hline Frequency of medicines & \multicolumn{4}{|c|}{$1=$ Once per day $; 2=$ Twice per day $3=$ Three per day $4=$ More than three times per day } \\
\hline
\end{tabular}

Primary caregivers need to set dummy variables

As suggested from the results here, participants scored higher on the cost burden domain, which is probably explained by their children's support. Besides, some medicines are not included in the medical insurance system. This complies with the results of an American survey on the cost of daily medication for 8777 patients $\geq$ 65 years of age [30]. Thus, despite the long-term multidrug elderly patients receiving medical insurance, the expensive medicines costs remain related to the medication burden. In addition, China's basic medical insurance system is impacted by several factors (e.g., economic foundations and institutional settings) and exhibits a certain degree of regionalization. Moreover, some chronic diseases and related medicines are not covered by medical reimbursement. Accordingly, the government should vigorously facilitate the rectification and reform of medical insurance [31], implement innovative outpatient chronic disease management, implement family doctors' contracted services, and soundly operate chronic disease prescriptions [32].
As revealed from the results of this study, the medication burden was more significant when the participants were aged 60-69 years. This result does not comply with the other studies reporting that those with older ages have lower medication burden [24,33]. The reason may be that the patients included in this study were aged $(73.57 \pm 7.87)$ years, older patients may take medication for a longer period and can more effectively develop a strategy in line with self-medication habits. Furthermore, older patients have relatively low expectations of medicines treatment [14] and have low perception of the impact of medicines interfering with their daily lives. Several patients enjoy medical insurance policy subsidies, and the cost burden of medication is relatively light. Some patients maintain good communication with medical staff $[34,35]$.

Under higher participants' educational level and economic income, the patients' multiple medication burden level was lower, which may be related to their less economic burden, and the patients with higher education

Table 5 Multivariable stepwise linear model analysis for the association with the multiple medication burden among elderly patients with chronic diseases $(n=430)^{a}$

\begin{tabular}{|c|c|c|c|c|c|}
\hline Variables((Reference) & $\beta$ & $95 \% \mathrm{Cl}$ & $S E$ & $t$ & $P$ value \\
\hline Age(per 10 years) & -2.044 & $(-3.296 ;-0.793)$ & 0.637 & -3.211 & 0.001 \\
\hline Education(College or above) & -1.960 & $(-3.010 ;-0.911)$ & 0.534 & -3.671 & $<0.001$ \\
\hline Income per month(RMB>4000) & -1.799 & $(-2.806 ;-0.791)$ & 0.513 & -3.508 & $<0.001$ \\
\hline Types of medicines $(>11)$ & 3.728 & $(2.381 ; 5.075)$ & 0.685 & 5.441 & $<0.001$ \\
\hline Monthly self-paid medication(RMB>800) & 2.125 & $(1.293 ; 2.957)$ & 0.423 & 5.022 & $<0.001$ \\
\hline Frequency of medicines ( $\geq 3$ times daily) & 3.213 & $(2.168 ; 4.258)$ & 0.532 & 6.043 & $<0.001$ \\
\hline Constant & 101.03 & $(92.956 ; 109.104)$ & 4.108 & 24.596 & 0.000 \\
\hline
\end{tabular}

$R^{2}=0.345$, Adj $R^{2}=0.329 ; F=10.31, P<0.0001$

${ }^{a}$ Adjustment for age $(60-69,70-79, \geq 80)$, education level (Primary school or less, Middle school, High school, College or above), Income per month(RMB) (< 2000,2000 ,3000 ,>4000), Types of medicines $(5 \sim 10,11 \sim 15,>15)$, Frequency of medicines (Once per day, Twice per day, Three per day, More than three times per day), Monthly self-paid medication(RMB) $(100,100 \sim, 300 \sim, 500 \sim, 800 \sim)$ and other variables in the models 
level would actively seek other medical resources (e.g., medication help and medication information [36, 37]). Moreover, participants with high education level have higher health literacy and medication literacy level, so the medication adherence can be improved [35, 38].

Complying with the expectation, high or frequent use of medicines was associated with higher C-LMQ-3 scores; multiple linear regression suggested an association $(P<0.001)$ and higher scores between the use of $\geq$ 11 medicines per day or $\geq 3$ times a day. The reason may be that when the patients use more types of medicines per day, more time, energy, emotion and money spent on medication practice management $[25,39]$ (e.g., medicine selection, medicine reserve, medicine-related precautions, medicine collocation taboo, medicine purchase that will aggravate their medication burden [40, 41]).

There are several strengths in this study. First, this is the study to initially investigate the factors of the burden of medication in the long-term multi-medicines use of elderly patients diagnosed with chronic diseases in Chinese mainland. Second, this study assessed the various aspects of medication burden of elderly patients diagnosed with chronic diseases during the long-term use of multiple medicines, which can help gain insights into the daily medication experience of patients. Third, health care providers can draw upon this study to screen chronic diseases patients who require medication and provide interventions to reduce the burden of medication. Fourth, a validated tool of C-LMQ-3 was adopted to measure medication burden, which led to the validity of the study results.

The limitations of this study should be acknowledged. First, a convenience sample of elderly participants with chronic disease was employed which was drawn only from Zhengzhou community in China. Whether and to what extent they can represent other elderly patients with chronic disease population in China requires indepth investigation. For this reason, the generalizability of our findings may be limited. Second, the sample size here was limited. In subsequent research, multi-center and large-sample studies should be conducted in other regions of China to verify whether the survey results here can be confirmed in other Chinese populations.

\section{Conclusions}

This study presents the preliminary evidence to elderly patients diagnosed with chronic diseases in mainland China, stressing that multiple medications burden may help reduce the drug related problems, especially domains of cost-related burden, concerns about medicines, and the lack of autonomy over medicine regimens. Those elderly patients with low education level, aged 60-69 years, using $\geq 11$ medicines, using medicines $\geq 3$ times a day, income per month $(\mathrm{RMB}) \leq 3000$, and monthly self-paid medication $(\mathrm{RMB}) \geq 300$ have a higher burden of medication. It is therefore suggested that Chinese health care providers should focus on evaluating and stress such patients, and formulate relevant intervention strategies to ensure medication adherence and daily medication management of elderly patients with polypharmacy use.

\section{Abbreviations}

C-LMQ-3: The Chinese version of Living with Medicines Questionnaire-3: WHO: World Health Organization; COPD: Chronic obstructive pulmonary disease; DRPs: Drug Related Problems; LMQ: The Living with Medicines Questionnaire; VAS: Visual analogue scale; RMB: Renminbi

\section{Acknowledgements}

We would like to thank all participants, researchers and community workers for their contributions to this work, and we are also grateful to Professor Janet Krska for hers suggestions on the revision of this paper.

\section{Authors' contributions}

YW and ZZ drafted the outline of this study. YW, BL, BF, BQ were responsible for collecting the data. YW, XL, DJ, BF and BQ performed data management, and $\mathrm{YW}, \mathrm{ZZ}$, and $\mathrm{XL}$ performed the data analysis. All co-authors critically reviewed the first results. YW drafted the first manuscript, and $Z Z, X L, D J, B L$, $\mathrm{BF}$, and $\mathrm{BQ}$ gave critical feedback. All authors have read and approved the final manuscript.

\section{Funding}

This study was funded by Science and Technology Department of Henan Province (No. 182102310198), and General research project of Humanities and social sciences of Henan Provincial Department of Education(No. 2018ZZJH-547)

\section{Availability of data and materials}

The data set used and analyzed in this study can be obtained from the corresponding author according to relevant reasonable requirements.

\section{Declarations}

Ethics approval and consent to participate

This study was approved by the Zhengzhou University ethical committee in China. During the investigation, we obtained the informed consent of the head of the community service center, all researchers and participants. We actively introduced the purpose and significance of this study to the participants, we also assured the participants that their responses would be anonymous and personal information confidential, prior to them signing the informed consent form. Also, the methods involved in our research are carried out in accordance with relevant guidelines and regulations (Declaration of Helsinki).

Consent for publication

Not applicable.

Competing interests

The authors report no conflicts of interest in this work.

\section{Author details}

${ }^{1}$ School of Nursing and Health, Zhengzhou University, No.100 Science Avenue, Henan, Zhengzhou, China. 'Peking University People's Hospital, Xicheng Dist, Beijing, China.

Received: 1 February 2021 Accepted: 23 April 2021

Published online: 13 May 2021

References

1. Affairs U N D O. World Population Ageing 2019. [EB/OL].[10.28]. https:// www.un.org/en/sections/issues-depth/ageing/. 
2. YAN Wei L Y Z R. Multimorbidity status of the elderly in China-research based on CHARLS data[J]. Chinese Journal of Disease Control \& Prevention, 2019,23(4):426-430.

3. Yun C, Man X, Bing L, et al. Analysis on non-communicable chronic diseases status and its influencing factors among the elderly in the northwest part of Hubei Province[J]. Chinese Journal of Prevention and Control of Chronic Diseases, 2015,23(2):85-88.

4. Wang S B, D'Arcy C, Yu Y Q, et al. Prevalence and patterns of multimorbidity in northeastern China: a cross-sectional study[]]. Public Health, 2015,129(11): 1539-1546.

5. Zhao Y, Atun R, Oldenburg B, et al. Physical multimorbidity, health service use, and catastrophic health expenditure by socioeconomic groups in China: an analysis of population-based panel data[J]. Lancet Glob Health, 2020,8(6):e840-e849.

6. R Z, Yun L, Shanshan Z, et al. Prevalence pattern and component correlation of chronic disease comorbidity among the elderly in China[J]. Chinese Journal of Public Health, 2019,25(8):1003-1005.

7. Xiaolan $\mathrm{H}$. Investigation on the current situation of comorbidity of chronic diseases in the community[D]. Beijing: Capital medical university, 2015.

8. Abdulah R, Insani W N, Destiani D P, et al. Polypharmacy leads to increased prevalence of potentially inappropriate medication in the Indonesian geriatric population visiting primary care facilities[]]. Ther Clin Risk Manag, 2018,14:1591-1597.

9. Yang $M, L u ~ J, ~ H a o ~ Q$, et al. Does residing in urban or rural areas affect the incidence of polypharmacy among older adults in western China?[]]. Arch Gerontol Geriatr, 2015,60(2):328-333.

10. Morin $L$, Johnell $K$, Laroche $M L$, et al. The epidemiology of polypharmacy in older adults: register-based prospective cohort study[]]. Clin Epidemiol, 2018,10:289-298

11. Mendonca P, Feitosa R P, Magalhaes S. The critical role of comorbidities and polypharmacy in lower risk myelodysplastic patients: is there any difference between countries?[J]. Med Oncol, 2018,35(11):143.

12. Gnjidic D, Tinetti M, Allore H G. Assessing medication burden and polypharmacy: finding the perfect measure[]]. Expert Rev Clin Pharmacol, 2017,10(4):345-347.

13. Lai XXZ H W H. The current status and associated factors of medication compliance in the elderly undergoing polypharmacy[]]. Chinese Nursing Management, 2016,16(12):1624-1638.

14. Ulley J, Harrop D, Ali A, et al. Deprescribing interventions and their impact on medication adherence in community-dwelling older adults with polypharmacy: a systematic review[]]. BMC Geriatr, 2019,19(1):15.

15. Hanlon J T, Zhao X, Naples J G, et al. Central Nervous System Medication Burden and Serious Falls in Older Nursing Home Residents[]]. J Am Geriatr Soc, 2017,65(6):1183-1189.

16. Mohammed M A, Moles R J, Chen T F. Medication-related burden and patients' lived experience with medicine: a systematic review and metasynthesis of qualitative studies[J]. BMJ Open, 2016,6(2):e10035.

17. van der Laan D M, Elders P J M, Boons C C L M, et al. The impact of cardiovascular medication use on patients' daily lives: a cross-sectional study[J]. International Journal of Clinical Pharmacy, 2018,40(2):412-420.

18. Krska J, Morecroft C W, Rowe P H, et al. Measuring the impact of long-term medicines use from the patient perspective[J]. International Journal of Clinical Pharmacy, 2014,36(4):675-678.

19. Krska J, Katusiime B, Corlett S A. Validation of an instrument to measure patients' experiences of medicine use: the Living with Medicines Questionnaire[]]. Patient Prefer Adherence, 2017,11:671-679.

20. Katusiime B, Corlett S, Krska J. Development and validation of a revised instrument to measure burden of long-term medicines use: the Living with Medicines Questionnaire version 3. 2018,Volume 9:155-168.

21. Krska J, Morecroft CW, Poole $\mathrm{H}$, et al. Issues potentially affecting quality of life arising from long-term medicines use: a qualitative study[]]. Int J Clin Pharm, 2013,35(6):1161-1169.

22. Carter S R, Bulanadi M G, Katusiime B, et al. Comprehensibly measuring patients' subjective thoughts, feelings and experiences of living with medicines: the Living with Medicines Questionnaire (LMQ)[J]. INTERNAT IONAL JOURNAL OF CLINICAL PHARMACY, 2015,37(2):424-425.

23. Wuyts J, Maesschalck J, De Wulf I, et al. Studying the impact of a medication use evaluation by the community pharmacist (Simenon): Patient-reported outcome measures[]]. Research in Social and Administrative Pharmacy, 2020
24. Tordoff J M, Brenkley C, Krska J, et al. Exploring Medicines Burden Among Adults in New Zealand: A Cross-Sectional Survey[J]. Patient preference and adherence, 2019,13:2171-2184.

25. Krska J, Corlett S, Katusiime B. Complexity of Medicine Regimens and Patient Perception of Medicine Burden[J]. Pharmacy, 2019,7(1):18.

26. Wang Y, Krska J, Lin B, et al. Cross-Cultural Adaptation and Reliability Testing of Chinese Version of the Living with Medicines Questionnaire in Elderly Patients with Chronic Diseases[J]. Patient Prefer Adherence, 2020,14:24772487.

27. LIU Fei $L$ Y C Q. Investigation of the affordability of chronic diseases drug use in families from three provinces in Western China[J]. Chinese Journal of Health Policy, 2017,10(12).

28. Faul F, Erdfelder E, Buchner A, et al. Statistical power analyses using G*Power 3.1: tests for correlation and regression analyses[]]. Behav Res Methods, 2009,41(4):1149-1160

29. Braitman L E. Statistical power analysis in medical research[J]. Ann Intern Med, 1983,99(2):269-271

30. Burcu M, Alexander G C, Ng X, et al. Construct validity and factor structure of survey-based assessment of cost-related medication burden[]]. Med Care, 2015,53(2):199-206.

31. XinChun Z, Ruiltong Z, Qingwen Q, et al. Discussion on Chronic Diseases Management from Perspective of Medical Insurance[J]. 2018,31(2):42-44.

32. Hongmei $Y$, Jing $W$, Junhua $Z$. Analysis of chronic disease long prescription in Shanghai based on the stakeholders theory[]]. Chinese Hospitals, 2016,20(4):52-54.

33. Krska J, Katusiime B, Corlett S A. Patient experiences of the burden of using medicines for long-term conditions and factors affecting burden: A crosssectional survey[]]. Health \& Social Care in the Community, 2018,26(6):946-959.

34. Weir K, Nickel B, Naganathan V, et al. Decision-Making Preferences and Deprescribing: Perspectives of Older Adults and Companions About Their Medicines[J]. J Gerontol B Psychol Sci Soc Sci, 2018,73(7):e98-e107.

35. Gomes D, Placido A I, Mo R, et al. Daily Medication Management and Adherence in the Polymedicated Elderly: A Cross-Sectional Study in Portugal[J]. Int J Environ Res Public Health, 2019,17(1).

36. Beuscart J B, Petit S, Gautier S, et al. Polypharmacy in older patients: identifying the need for support by a community pharmacist[]]. BMC Geriatr, 2019,19(1):277.

37. Cutler R L, Fernandez-Llimos F, Frommer M, et al. Economic impact of medication non-adherence by disease groups: a systematic review[J]. BMJ Open, 2018,8(1):e16982.

38. Zhong Z, Zheng F, Guo Y, et al. Medication Literacy in a Cohort of Chinese Patients Discharged with Acute Coronary Syndrome. Int J Environ Res Public Health, 2016;13:7.

39. WANG Yongli, LUAN Wenyan, GUO Yawen, et al. Multiple Medication Experience of Elderly Patients with Multimobidity at Home:a Qualitative Study[J]. Chinese General Practice, 2020,23(17):2197-2202.

40. Wimmer B C, Cross A J, Jokanovic N, et al. Clinical Outcomes Associated with Medication Regimen Complexity in Older People: A Systematic Review[J]. J Am Geriatr Soc, 2017,65(4):747-753.

41. Swain L, Barclay L. They've given me that many tablets, I'm bushed. I don't know where I'm going: Aboriginal and Torres Strait Islander peoples' experiences with medicines[]]. Aust J Rural Health, 2013,21(4):216-219.

\section{Publisher's Note}

Springer Nature remains neutral with regard to jurisdictional claims in published maps and institutional affiliations.

Ready to submit your research? Choose BMC and benefit from:

- fast, convenient online submission

- thorough peer review by experienced researchers in your field

- rapid publication on acceptance

- support for research data, including large and complex data types

- gold Open Access which fosters wider collaboration and increased citations

- maximum visibility for your research: over $100 \mathrm{M}$ website views per year

At $\mathrm{BMC}$, research is always in progress.

Learn more biomedcentral.com/submission 